\title{
An Ultra-thin Compact Wideband Metamaterial Absorber
}

\author{
RAMYA Sekar, SRINIVASA RAO Inabathini \\ School of Electronics Engineering, VIT University, Vellore, Tamilnadu, India \\ ramya.sekar@vit.ac.in, israo@vit.ac.in
}

Submitted April 24, 2017 / Accepted April 16, 2018

\begin{abstract}
This article reports an ultra-thin, compact metamaterial absorber with wideband absorption at microwave frequencies. The proposed structure contains circular and rectangular split rings, and has thickness of $0.049 \lambda_{0}$ with respect to the center frequency of the bandwidth. This structure provides wideband absorption of $3.84 \mathrm{GHz}$ from $12.80 \mathrm{GHz}$ to $16.64 \mathrm{GHz}$ with $90 \%$ absorptivity and absorption peaks are observed at $13.2 \mathrm{GHz}$ and $16.5 \mathrm{GHz}$. The full width half maximum of the structure is $5.48 \mathrm{GHz}$ from $12.09 \mathrm{GHz}$ to $1757 \mathrm{GHz}$. The absorption mechanism and polarization behavior of the structure have to be studied. The proposed metamaterial absorber is sensitive to polarization but wideband absorption is attained only for specific normal and oblique angles of incidence, with reduced absorptivity. The structure has been fabricated, and the measured results match well with the simulation responses. The advantage of the proposed absorber is its wideband absorption with compact $(8 \mathrm{~mm} \times 8 \mathrm{~mm}$ size), ultra-thin (1 $\mathrm{mm}$ thick substrate) structure compared to that of the other existing microwave metamaterial absorbers.
\end{abstract}

\section{Keywords}

Microwave absorber, metamaterial, wideband absorber, ultra-thin

\section{Introduction}

Metamaterial [1], an artificial structure with unique properties has attracted attention in applications such as antenna [2-6], cloaking [7-9], absorbers [10], [11], and so on. In recent years, metamaterial absorbers have been used as promising alternative for conventional absorbers owing to their perfect electromagnetic absorption, compact size, ultra-thin thickness, and low profile design. These advantages have led to different microwave metamaterial absorbers in single band [12], [13], dual band [14], [15], multi-band [16-18] and wideband [19] applications in all frequency regimes [20], [21]. Though metamaterial absorber has various benefits, it suffers from narrow bandwidth. Metamaterial absorbers with multiple dielectric layers [22], [23] are used for enhancing the absorption bandwidth but huge thickness is the major constraint in many applications. Multi-resonant [24] structures were proposed as wideband absorbers. These absorbers are the combination of multiple resonant structures exhibiting enhanced absorption bandwidth. The major limitations of these absorbers are their large size and the difficulty in controlling the structure at each absorption frequency. Single layer metamaterial absorbers [25], [26] possess moderate structure thickness and have enhanced absorption bandwidth. These structures are low profile and can be easily optimized to control the resonant frequency. Interesting applications of metamaterial absorbers are: stealth technology, specific absorption rate (SAR) reduction and electromagnetic interference (EMI) suppression.

This article proposes a compact, wideband metamaterial absorber with $0.049 \lambda_{0}$ thickness operating at microwave frequencies. The proposed structure with circular and rectangular split rings provides absorption of $3.84 \mathrm{GHz}$ at $90 \%$ absorptivity and full width half maximum (FWHM) of $5.48 \mathrm{GHz}$. This asymmetric structure is polarization sensitive. The electromagnetic field and surface current distributions were analyzed for the absorption mechanism of the proposed metamaterial absorber.

\section{Structure Design and Simulation Results}

The design of the proposed wideband microwave metamaterial absorber is presented in Fig. 1 with electromagnetic field vector directions. The top layer of the unit cell consists of outer rectangular split ring and inner two circular split rings with dimensions $a=8 \mathrm{~mm}, b=3 \mathrm{~mm}$, $c=3.5 \mathrm{~mm}, d=2.5 \mathrm{~mm}, e=2.7 \mathrm{~mm}, g_{1}=0.5 \mathrm{~mm}$, $g_{2}=1.5 \mathrm{~mm}, g_{3}=0.8 \mathrm{~mm}, g_{4}=0.7 \mathrm{~mm}, g_{5}=0.6 \mathrm{~mm}, g_{6}=$ $0.45 \mathrm{~mm}, w_{1}=0.35 \mathrm{~mm}, w_{2}=0.4 \mathrm{~mm}, w_{3}=0.5 \mathrm{~mm}, w_{4}=$ $0.5 \mathrm{~mm}, r_{1}=2.55 \mathrm{~mm}$ and $r_{2}=1.9 \mathrm{~mm}$. The top layer metallic patch is etched on FR4 dielectric substrate of $1 \mathrm{~mm}$ thickness and dielectric permittivity $\varepsilon_{\mathrm{r}}=4.4$. The other side of dielectric substrate is complete copper ground (conductivity $=5.8 \times 10^{7} \mathrm{~S} / \mathrm{m}$, thickness $\left.=0.035 \mathrm{~mm}\right)$. The designed structure is simulated using Ansys HFSS with periodic boundary conditions and Floquet port excitations. The proposed structure is chosen such that each part of the 


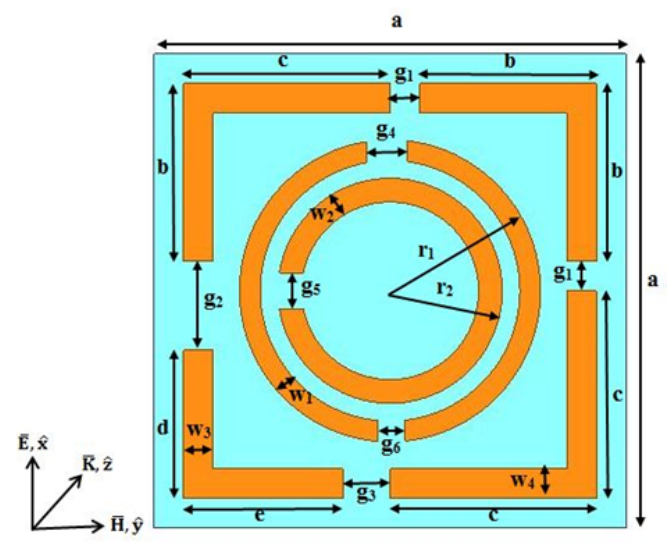

Fig. 1. Top layer of the proposed unit cell structure.

structure resonates at particular frequency. The inner most circular split ring and the outer rectangular ring resonate at 16.69 GHz and 13.29 GHz, respectively. Then, the middle ring was incorporated and the structure was optimized to provide wideband absorption.

The absorptivity $A(\omega)$ of the structure is given by (1) [27] where $S_{21}(\omega)$ and $S_{11}(\omega)$ are the ratios of the transmitted and reflected power to the incident power, respectively. The complete copper ground blocks the transmission of electromagnetic waves $\left(\left|S_{21}(\omega)\right|=0\right)$ and therefore the absorptivity can be increased by reducing the reflection from the absorber structure. The proposed structure provides wideband absorption of $3.84 \mathrm{GHz}$ at $90 \%$ absorptivity with two absorption peaks at $13.2 \mathrm{GHz}$ and $16.5 \mathrm{GHz}$ as shown in Fig. 2(a) and has FWHM of $5.48 \mathrm{GHz}$. The patch design and thickness of the dielectric substrate are optimized to match the free space impedance with the input impedance of the structure. The normalized input impedance $(Z(\omega))$ is given by (2) [27], and is shown in Fig. 2(b). At the absorption peaks, the imaginary and real parts of the normalized input impedance become zero and unity, respectively. The unity real part indicates the perfect impedance matching of the structure which leads to the maximum absorption.

$$
\begin{gathered}
A(\omega)=1-\left|S_{11}(\omega)\right|^{2}-\left|S_{21}(\omega)\right|^{2}, \\
Z(\omega)=\frac{1+S_{11}(\omega)}{1-S_{11}(\omega)}, \\
\chi_{\mathrm{es}}=\frac{2 \mathrm{j} S_{11}-1}{k_{0} S_{11}+1}, \\
\chi_{\mathrm{ms}}=\frac{2 \mathrm{j} S_{11}+1}{k_{0} S_{11}-1}, \\
\varepsilon_{\mathrm{eff}}=1+\frac{\chi_{\mathrm{es}}}{d}, \\
\mu_{\mathrm{eff}}=1+\frac{\chi_{\mathrm{ms}}}{d} .
\end{gathered}
$$

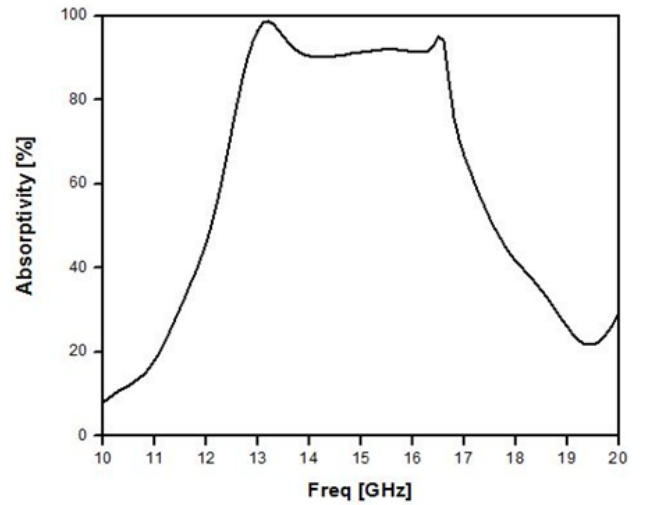

(a)

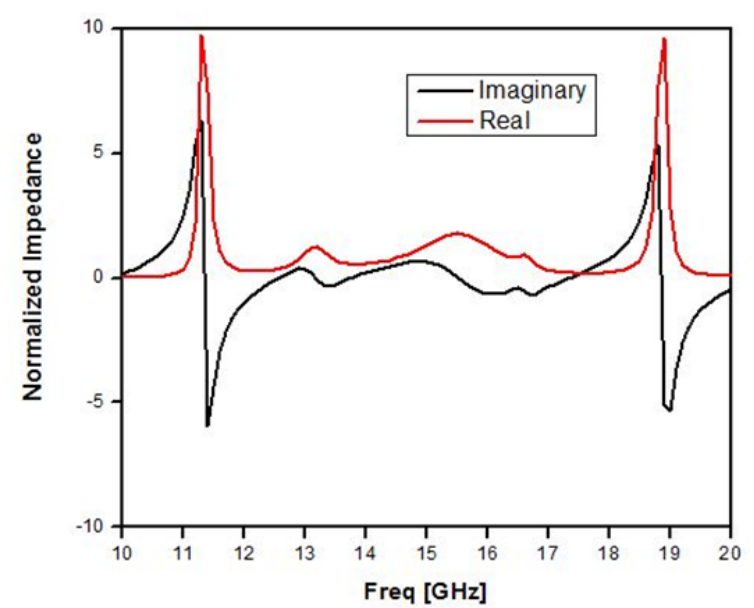

(b)

Fig. 2. (a) Simulated absorptivity and (b) normalized impedance.

The effective permittivity $\varepsilon_{\text {eff }}$ and effective permeability $\mu_{\text {eff }}$ are calculated using electric susceptibility $\chi_{\text {es }}$ and magnetic susceptibility $\chi_{\mathrm{ms}}$ as shown in (3), (4) (5) and (6) [27], where $k_{0}$ is the wavenumber of the free space and $d$ is the distance travelled by the incident electromagnetic wave. The retrieved real and imaginary parts of the electromagnetic parameters $\varepsilon_{\text {eff }}$ and $\mu_{\text {eff }}$ are shown in Figs. 3(a) and 3(b) and presented in Tab. 1. The negative $\varepsilon_{\text {eff }}$ and $\mu_{\text {eff }}$ confirm that the proposed structure is double negative metamaterial and behaves as absorber in microwave region.

The parametric analysis of the proposed structure and its impact on absorptivity are demonstrated in Fig. 4 and Fig. 5. The analyses were performed by varying one parameter while keeping the other parameters as constant under $0^{\circ}$ of normal and oblique angles of incidence. In Fig. 4, the lengths of the rectangular split ring are varied and their impact on absorptivity is studied. Figures 4(a) and 4(b) show the responses by varying the lengths $b$ and $c$ where the absorptivity decreases to less than $85 \%$ and $80 \%$, respectively. Also, the absorption bandwidth obtained is narrow. For variations in the lengths $d$ and $e$, the absorption bandwidth is retained, as shown in Fig. 4(c) and Fig. 4(d). However, the absorptivity decreases below $85 \%$ excluding $d=2.3 \mathrm{~mm}$ and $e=2.5 \mathrm{~mm}$. The other parameters like 


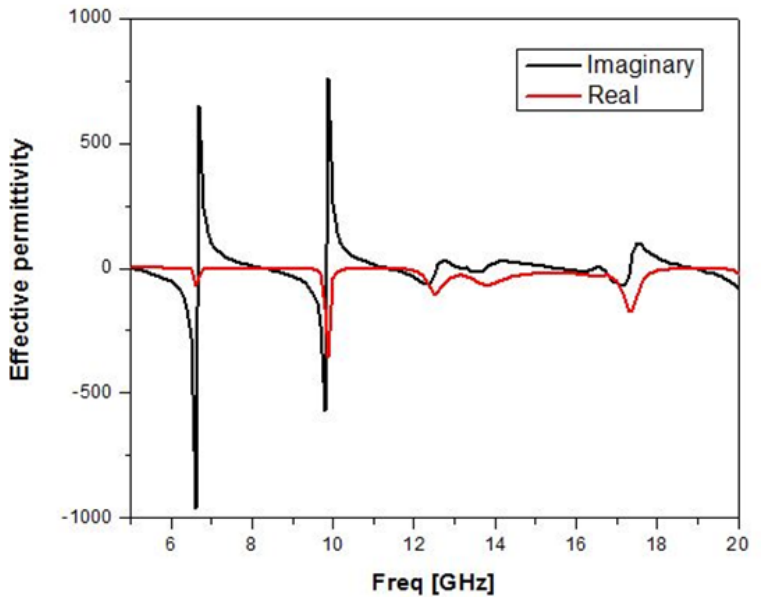

(a)

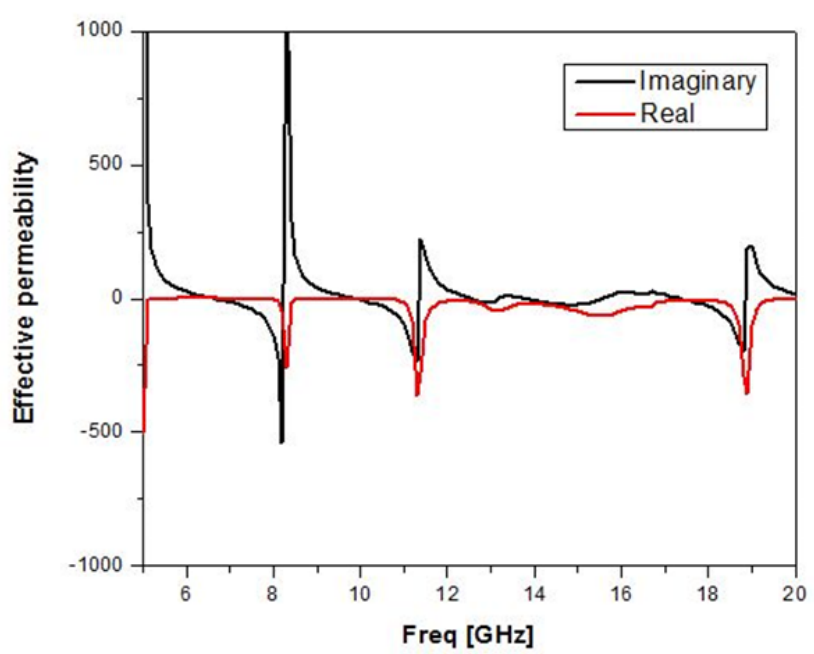

(b)

Fig. 3. Simulated electromagnetic parameters (a) effective permittivity and (b) effective permeability.

\begin{tabular}{|c|c|c|c|c|}
\hline $\begin{array}{c}\text { Frequency } \\
{[\mathbf{G H z}]}\end{array}$ & $\begin{array}{c}\text { Real } \\
\left(\boldsymbol{\varepsilon}_{\text {eff }}\right)\end{array}$ & $\begin{array}{c}\text { Real } \\
\left(\boldsymbol{\mu}_{\text {eff }}\right)\end{array}$ & $\begin{array}{c}\text { Imaginary } \\
\left(\boldsymbol{\varepsilon}_{\text {eff }}\right.\end{array}$ & $\begin{array}{c}\text { Imaginary } \\
\left(\boldsymbol{\mu}_{\text {eff }}\right)\end{array}$ \\
\hline 13.2 & -29.179 & -44.890 & 0.800 & 3.162 \\
\hline 16.5 & -34.853 & -30.820 & 1.805 & 14.915 \\
\hline
\end{tabular}

Tab. 1. The retrieved effective permittivity and effective permeability of the proposed metamaterial absorber.

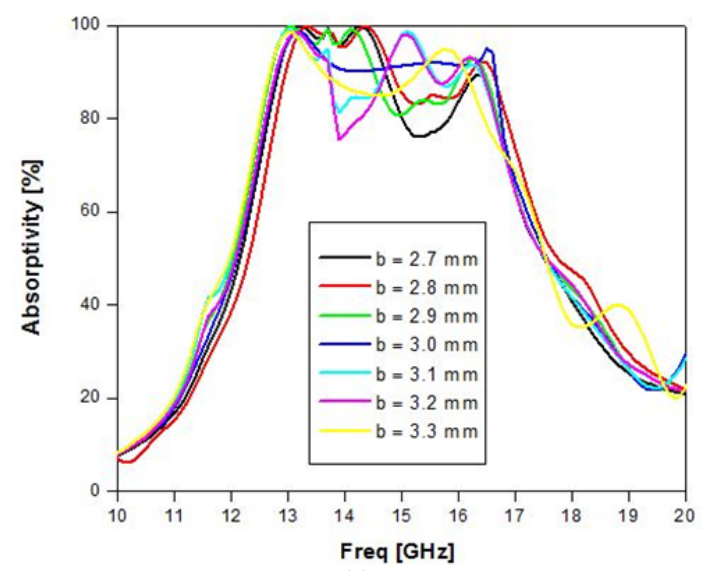

(a)

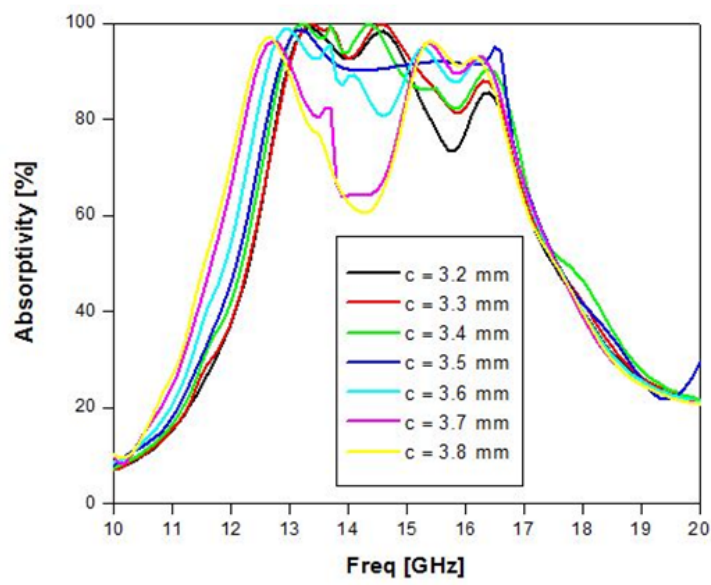

(b)

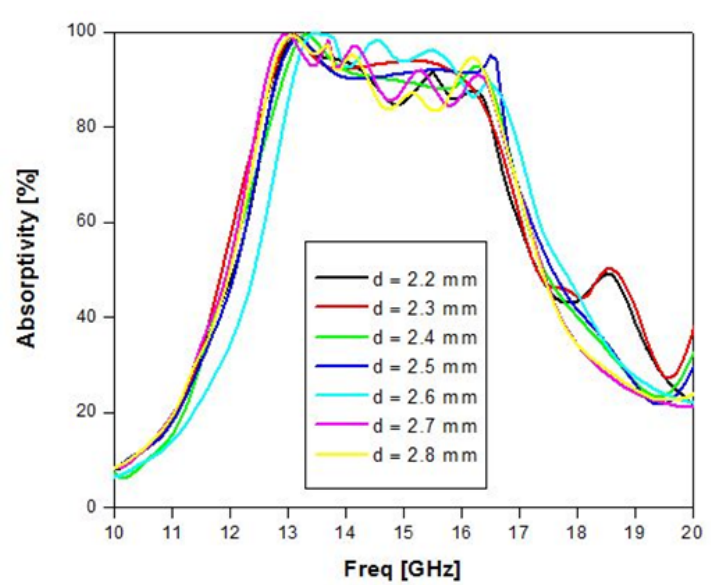

(c)

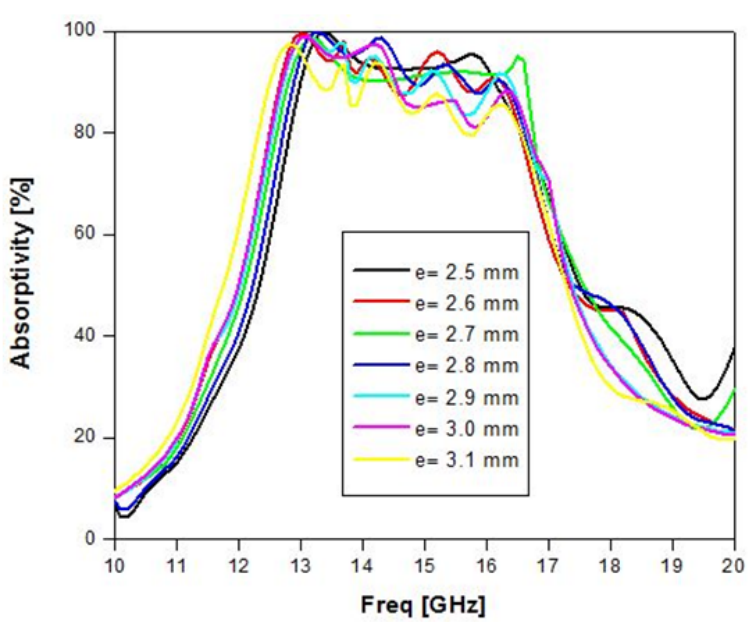

(d)

Fig. 4. Simulated absorptivities under variations of (a), (b), (c), (d) lengths of the rectangular split ring.

widths and gaps of the circular split ring are varied and the absorptivity is presented in Fig. 5. The outer ring width is varied; for small width, the absorptivity drops below $85 \%$ with wide absorption, however the bandwidth becomes narrow as the outer ring width increases, as shown in Fig. 5(a). The variations in the inner ring widths provide reduced absorptivity and narrow bandwidth as presented in Fig. 5(b). The gaps in the outer ring are varied and the 
responses are presented in Fig. 5(c) and Fig. 5(d). For $g_{4}=0.4 \mathrm{~mm}, 0.5 \mathrm{~mm}$ and $0.8 \mathrm{~mm}$, the absorptivity is above $90 \%$ with reduced bandwidth and other gap variations lead to very narrow bandwidth.

Figure 5(d) represents the absorptivities by varying the gap $g_{6}$ at the bottom of the outer ring. It indicates that both the absorptivity and bandwidth are reduced except for

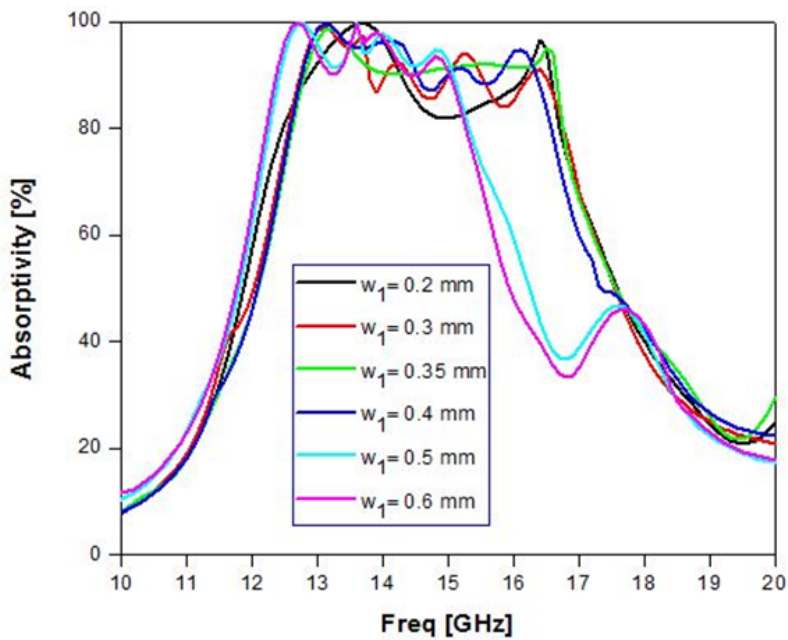

(a)

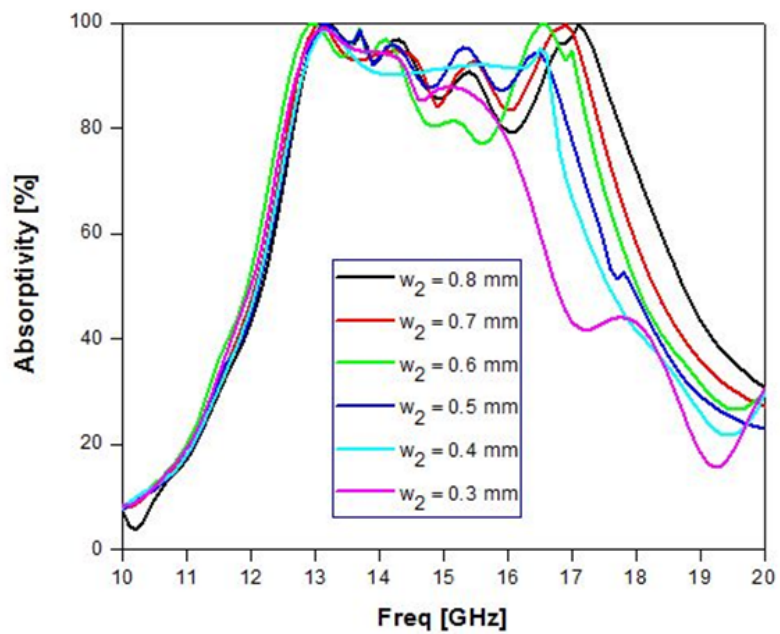

(b)

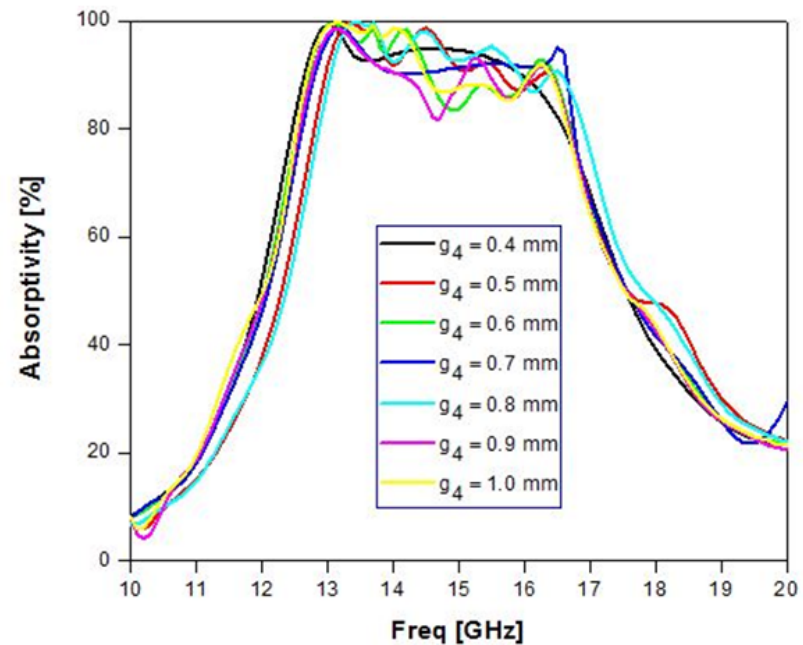

(c)

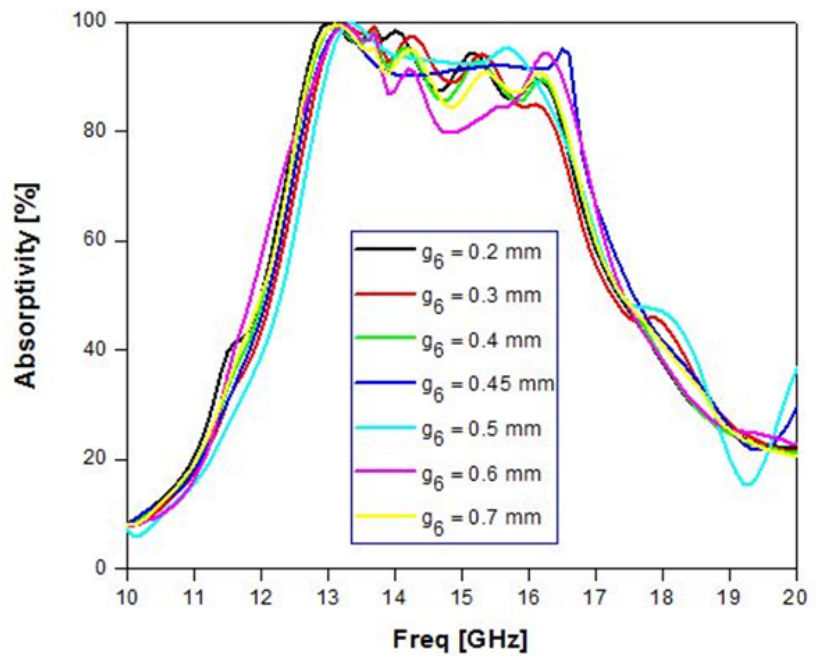

(d)

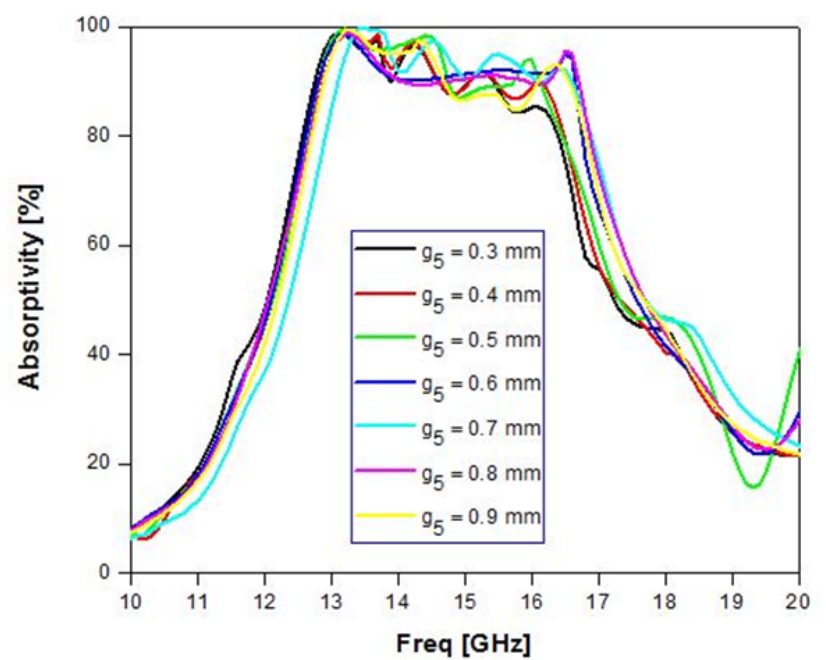

(e)

Fig. 5. Simulated absorptivities under variations of (a), (b) widths and (c), (d), (e) gaps of the of the circular split rings.

$g_{6}=0.5 \mathrm{~mm}$, where the absorptivity is above $90 \%$, and it has decreased absorption bandwidth. The absorptivity under variations of the inner ring gaps is presented in Fig. 5(e). It illustrates that absorptivity and bandwidth decreases, except for $g_{5}=0.8 \mathrm{~mm}$ where wide bandwidth is retained.

The distributions of electric and magnetic fields at the resonating frequencies are presented in Fig. 6 and Fig. 7, respectively. The magnetic and electric fields are highly concentrated in the rectangular split ring, contributing to high absorption at $13.2 \mathrm{GHz}$. At $16.5 \mathrm{GHz}$, the electromagnetic fields are higher in the circular split rings. The maximum absorption is obtained within the structure by the overlapping of electromagnetic fields. Figure 8 and Figure 9 show the surface currents distributed in the both layers of the proposed metamaterial absorber. At low frequency, the surface currents are mostly distributed in some parts of the rectangular and circular rings. Hence, both the rings contribute to high absorption at $13.2 \mathrm{GHz}$. whereas; absorption at $16.5 \mathrm{GHz}$ is mostly due to the surface currents in the inner circular ring and partially by rectangular 
ring excitation. The anti-parallel surface currents create circulating loops around the magnetic field incident on the top layer of the structure. At these resonating frequencies, the electric fields are coupled with the copper patch, which leads to high absorption.

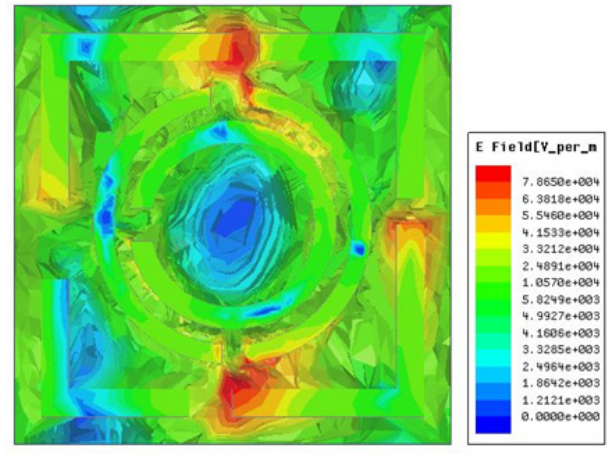

(a)

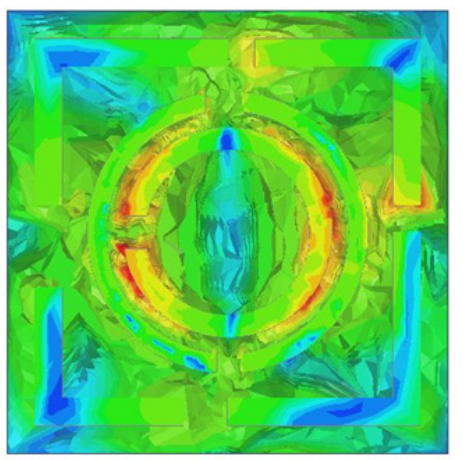

(b)

Fig. 6. Electric field distributions at (a) $13.2 \mathrm{GHz}$ and (b) $16.5 \mathrm{GHz}$.

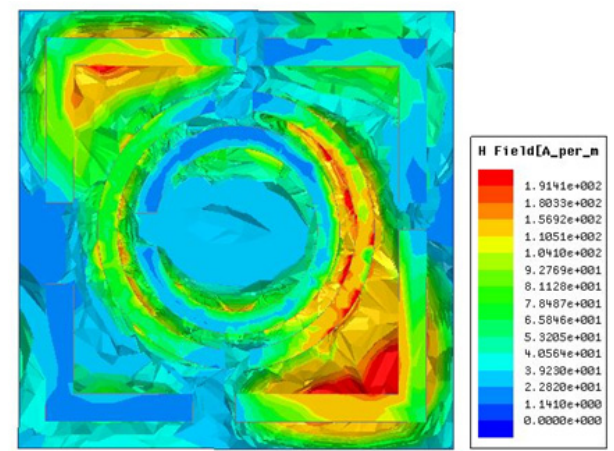

(a)

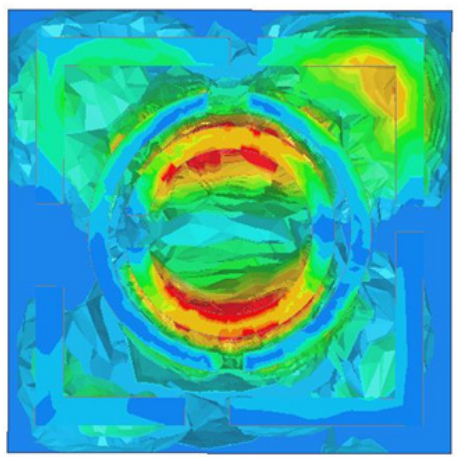

(b)

Fig. 7. Magnetic field distributions at (a) $13.2 \mathrm{GHz}$ and (b) $16.5 \mathrm{GHz}$.

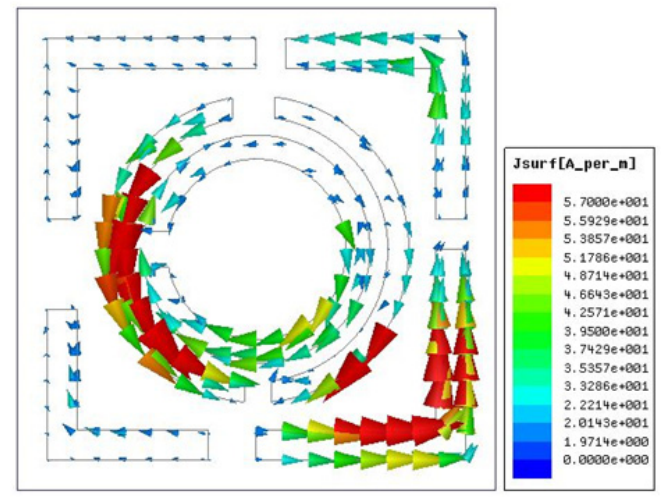

(a)

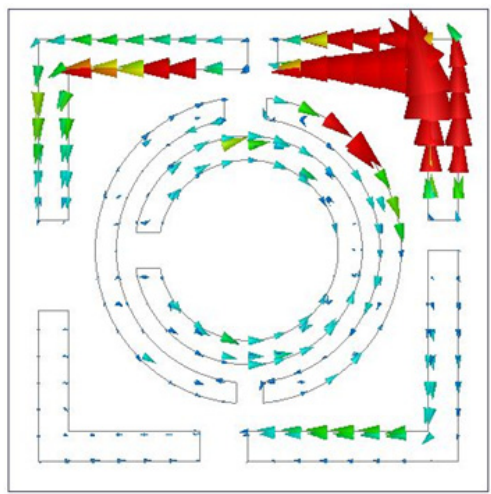

(b)

Fig. 8. Surface current distributions on top layer at (a) $13.2 \mathrm{GHz}$ and (b) $16.5 \mathrm{GHz}$.

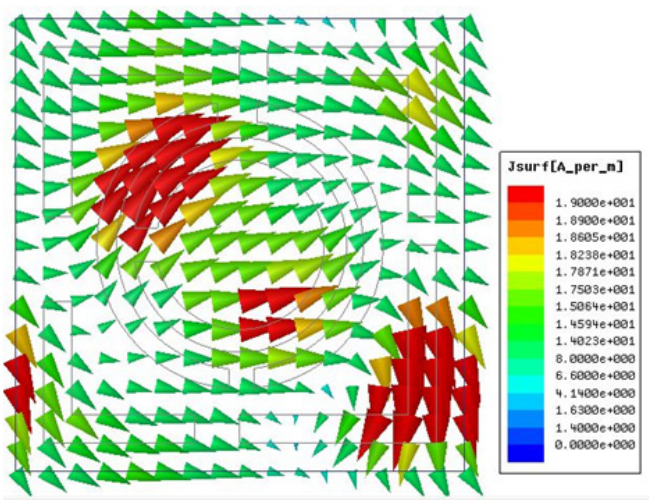

(a)

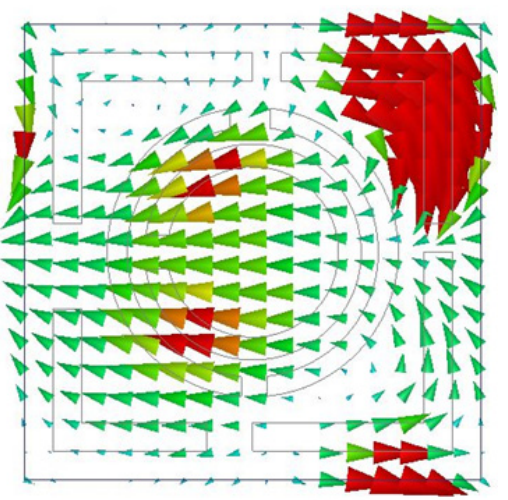

(b)

Fig. 9. Surface current distributions on bottom layer at (a) $13.2 \mathrm{GHz}$ and (b) $16.5 \mathrm{GHz}$. 
The polarization sensitivity of the proposed absorber is studied under oblique and normal angles of incidence for Transverse Electric (TE) mode. The electric field direction is fixed, and the wave vector and magnetic field directions are changed to analyze the absorptivities under oblique incidence. To test polarization behavior of the structure under normal incidence, the magnetic and electric field directions are changed while the wave propagating direction is made normal along $\mathrm{z}$ direction. Figure 10 (a) shows that, under oblique angles of incidence at $10^{\circ}, 15^{\circ}$ and $60^{\circ}$, the absorptivity drops to $78.7 \%, 71.1 \%$, and $77 \%$ with bandwidth of $4.12 \mathrm{GHz}, 4.28 \mathrm{GHz}$ and $4.21 \mathrm{GHz}$, respectively. At $25^{\circ}, 50^{\circ}$ and $85^{\circ}$, the absorptivity decreases to $85.6 \%, 82.8 \%$ and $80.4 \%$ with bandwidth of $3.86 \mathrm{GHz}$, $3.96 \mathrm{GHz}$ and $4.22 \mathrm{GHz}$, respectively. The polarization under normal angles of incidence is tested and analyzed in Fig. $10(\mathrm{~b})$. At $25^{\circ}, 35^{\circ}, 50^{\circ}, 60^{\circ}, 75^{\circ}$ and $85^{\circ}$, the absorptivity is reduced to $88.6 \%, 68.2 \%, 89.2 \%, 70.2 \%, 83.6 \%$ and $82.5 \%$ with bandwidth of $3.7 \mathrm{GHz}, 2.64 \mathrm{GHz}$, $3.57 \mathrm{GHz}, 4.29 \mathrm{GHz}, 3.77 \mathrm{GHz}$ and $3.70 \mathrm{GHz}$, respectively. The simulation results show the proposed structure is polarization sensitive and has wide bandwidth with reduced absorptivity at various angles.

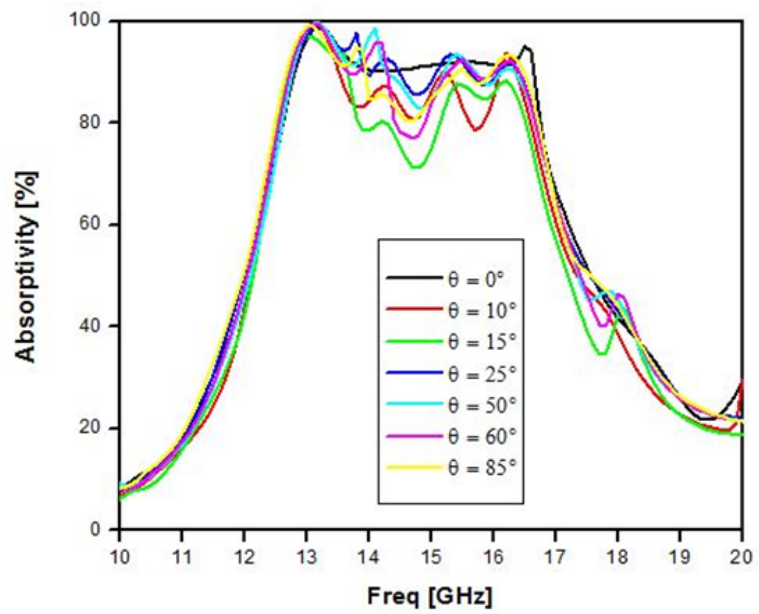

(a)

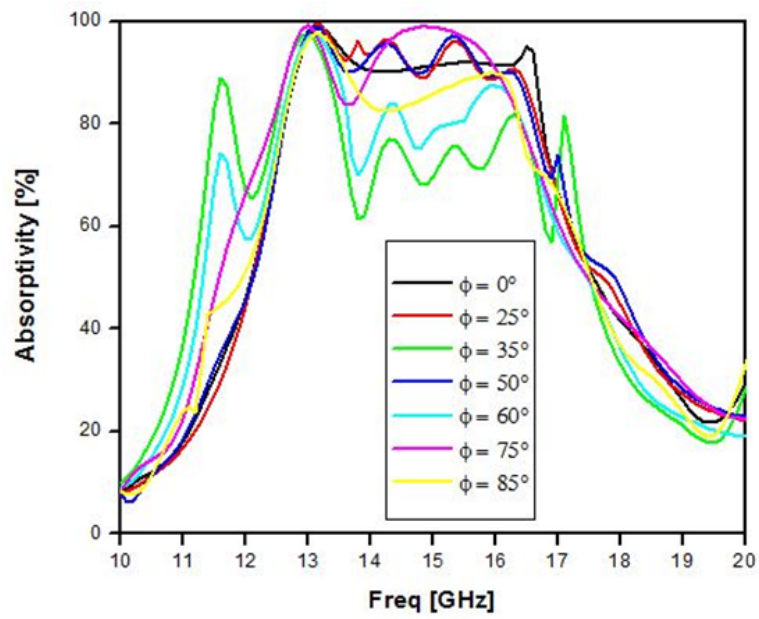

(b)

Fig. 10. Simulated absorptivities under (a) oblique and (b) normal incidence for TE polarization.

\section{Experimental Results and Analysis}

To perform experimental test, $40 \times 40$ array of the proposed unit cells with dimension $320 \times 320 \mathrm{~mm}$ was fabricated using printed circuit board (PCB) technology. This fabricated structure was tested in anechoic chamber, and the experimental measurement set up is shown in Fig. 11(a). It contained two broadband horn antennas operating at $2-18 \mathrm{GHz}$ which were connected to PNA Network Analyzer Agilent E8362B. These two antennas were used for transmitting the electromagnetic waves and receiving

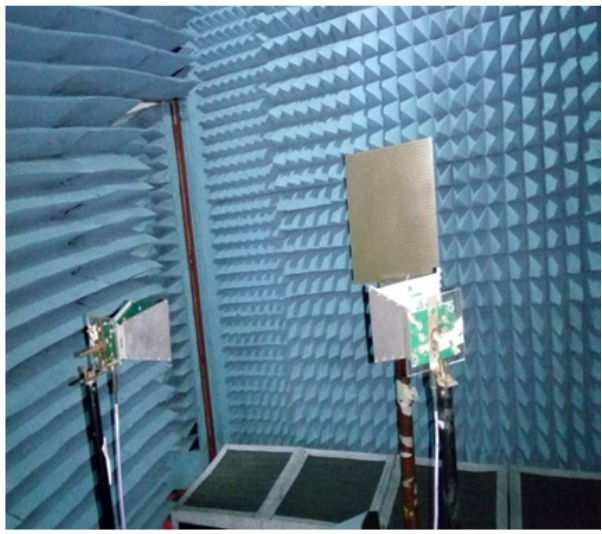

(a)

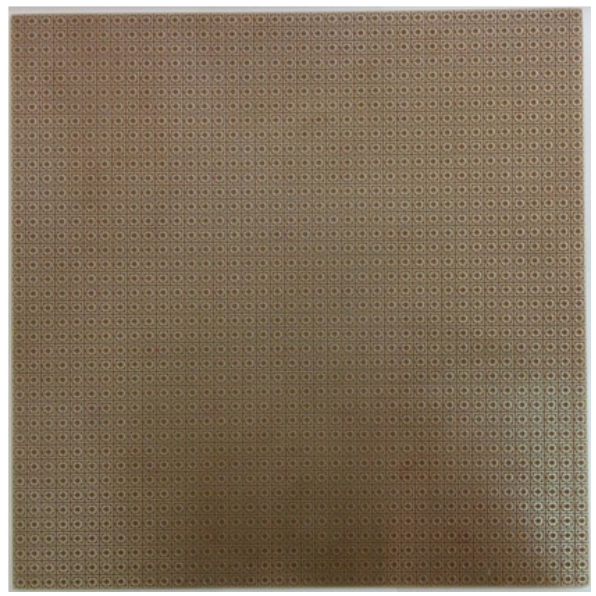

(b)

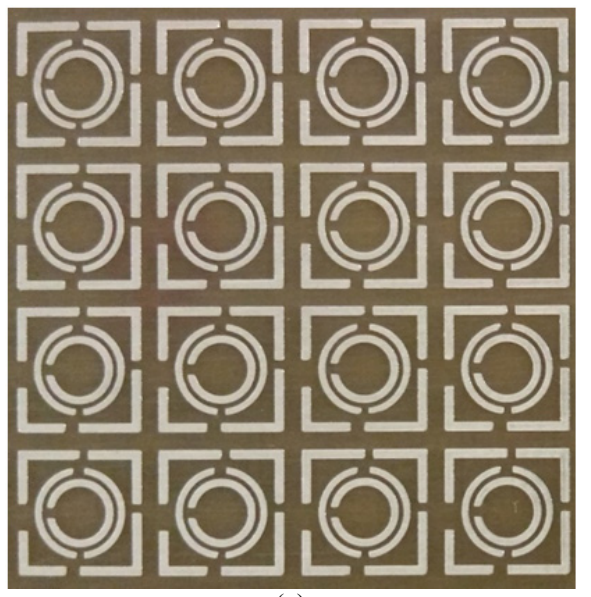

(c)

Fig. 11. (a) The experimental set up and (b) the fabricated absorber, with (c) the enlarged view. 


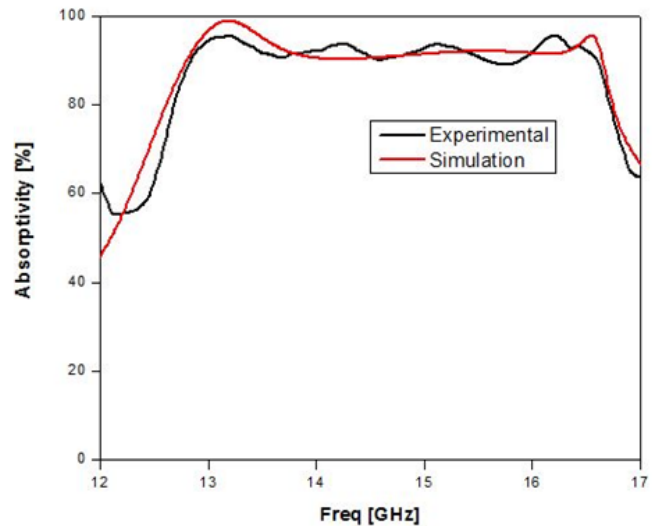

(a)

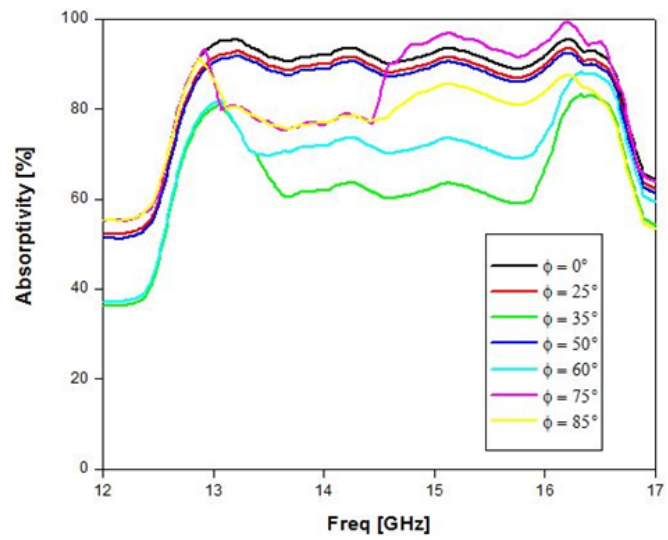

(b)

Fig. 12. (a) Comparison of measured and simulated absorptivity, and (b) measured absorptivity under TE mode for normal angles of incidence.

\begin{tabular}{|c|c|c|c|c|c|}
\hline Ref. & $\begin{array}{c}\text { Substrate } \\
\text { thickness } \\
{[\mathbf{m m}]}\end{array}$ & $\begin{array}{c}\text { Unit cell } \\
\text { size [mm] }\end{array}$ & $\begin{array}{c}\text { Frequency } \\
{[\mathbf{G H z}]}\end{array}$ & $\begin{array}{c}\text { Absorption } \\
\text { Bandwidth } \\
{[\mathbf{G H z}]}\end{array}$ & $\begin{array}{c}\text { Absorpti- } \\
\text { vity [\%] }\end{array}$ \\
\hline$[28]$ & 0.5 & 7.8 & 2.5 & $<0.5$ & 90 \\
\hline$[29]$ & 0.8 & 18 & $10.14,10.79$ & $<1$ & $\begin{array}{c}99.88, \\
99.67\end{array}$ \\
\hline$[30]$ & 0.8 & 20 & $\begin{array}{c}4.34,6.68, \\
8.58,10.64\end{array}$ & $<0.5$ & 90 \\
\hline$[31]$ & 1 & 7.2 & $9.66,10.26$ & $<1$ & $96,92.5$ \\
\hline$[32]$ & 1 & 11 & $\begin{array}{c}3.25,9.45, \\
10.90\end{array}$ & $<1$ & 90 \\
\hline$[33]$ & 1.6 & 7 & $\begin{array}{c}10.36 \text { to } \\
16.67\end{array}$ & 6.31 & 85 \\
\hline $\begin{array}{c}\text { Proposed } \\
\text { structure }\end{array}$ & 1 & 8 & $\begin{array}{c}12.80 \text { to } \\
16.64\end{array}$ & 3.84 & 90 \\
\hline
\end{tabular}

Tab. 2. Comparison of ultra-thin metamaterial absorbers.

the reflected power from the fabricated structure. The power measurements were calibrated and measured from the network analyzer. The fabricated structure with the enlarged view is presented in Fig. 11(b) and Fig. 11(c). In the anechoic chamber, a copper sheet of equal dimension as that of the fabricated structure was initially positioned and the reflected power was measured as the reference. Then, the fabricated structure was positioned at the same location of the copper sheet and the reflected power from the structure was measured. The difference between the reflected and the reference power gives the actual power reflections.

The simulated absorptivity was compared with the experimentally measured absorptivity in Fig. 12(a). The measured response showed wideband absorption of $3.92 \mathrm{GHz}$ which matched closely with the simulated response. The deviation in the measured and simulated absorptivity was due to the fabrication tolerances. The polarization sensitivity of the fabricated structure was tested under normal incidences for TE mode. The absorptivities under normal angles of incidence shown in Fig. 12(b) were measured by rotating the fabricated structure along its axis, with the antennas in static position. The result shows that, the structure is polarization sensitive and matches well with the simulated absorptivities under normal angles of incidence. The proposed metamaterial absorber is compared with ultra-thin structures in Tab. 2. Though previous structures were either ultra-thin or compact or both, the absorption bandwidths are very narrow when compared to the proposed structure. Table 2 confirms the advantage of the proposed absorber as wideband absorption of $3.84 \mathrm{GHz}$ with $1 \mathrm{~mm}$ thick substrate and compact $(8 \mathrm{~mm} \times 8 \mathrm{~mm}$ size) structure.

\section{Conclusion}

A wideband microwave metamaterial absorber with circular and rectangular split rings has been proposed. The structure is compact and ultra-thin $\left(0.049 \lambda_{0}\right.$ thick $)$. It is optimized to provide wideband absorption with two peaks at $13.2 \mathrm{GHz}$ and $16.5 \mathrm{GHz}$. The simulated results show $3.84 \mathrm{GHz}$ wideband absorption with $90 \%$ absorptivity and FWHM of $5.48 \mathrm{GHz}$. The electric field, magnetic field, and surface current distributions were analyzed distinctly at two absorption peaks to understand the absorption mechanism. The polarization behavior of the structure was examined for normal and oblique angles of incidence. The responses showed that the structure was polarization sensitive and for particular angles of incidence, wideband absorption was retained. However, the percentage of absorptivity reduced. The proposed metamaterial absorber has been fabricated and the practical measurements are similar to the simulated results. This microwave absorber with wideband absorption, ultra-thin and compact structure can be suitable for stealth and radar applications.

\section{Acknowledgment}

The authors acknowledge Dr. P. Mohanan, Department of Electronics, Cochin University of Science and Technology for the lab facility to conduct the experimental test of the fabricated structure. 


\section{References}

[1] SMITH, D. R., PADILlA, W. J., VIER, D. C., et al. Composite medium with simultaneously negative permeability and permittivity. Physical Review Letters, 2000, vol. 84, no. 18, p. 4184-4187. DOI: 10.1103 /PhysRevLett.84.4184

[2] LI, L. W., LI, Y. N., YEO, T. S., et al. A broadband and high-gain metamaterial microstrip antenna. Applied Physics Letters, 2010, vol. 96, no. 16, p. 164101-1-164101-3. DOI: 10.1063/1.3396984

[3] CALOZ, C., ITOH, T., RENNINGS, A. CRLH metamaterial leaky-wave and resonant antennas. IEEE Antennas and Propagation Magazine, 2008, vol. 50, no. 5, p. 25-39. DOI: 10.1109/MAP.2008.4674709

[4] ERENTOK, A., ZIOLKOWSKI, R. W. Metamaterial-inspired efficient electrically small antennas. IEEE Transactions on Antennas and Propagation, 2008, vol. 56, no. 3, p. 691-707. DOI: 10.1109/TAP.2008.916949

[5] PALANDOKEN, M. Artificial materials based microstrip antenna design. In Microstrip Antennas. Ed. Nasimuddin, N. InTechOpen, 2011 . Available

at:

https://www.researchgate.net/profile/Merih Palandoken/publicatio n/221911593_Artificial_Materials_based_Microstrip_Antenna_De sign/links/02 bfe50fdd7 $\overline{4}$ b35cb5000000/Artificial-Materials-basedMicrostrip-Antenna-Design.pdf DOI: 10.5772/14908

[6] PALANDÖKEN, M. Microstrip antenna with compact anti-spiral slot resonator for $2.4 \mathrm{GHz}$ energy harvesting applications. Microwave and Optical Technology Letters, 2016, vol. 58, no. 6, p. 1404-1408. DOI: $10.1002 / \mathrm{mop} .29824$

[7] CAI, W., CHETTIAR, U. K., KILDISHEV, A. V., et al. Optical cloaking with metamaterials. Nature Photonics, 2007, vol. 1, no. 4, p. 224-227. DOI: $10.1038 /$ nphoton. 2007.28

[8] ALU, A., ENGHETA, N. Achieving transparency with plasmonic and metamaterial coatings. Physical Review E, 2005, vol. 7, no. 1, p. 016623-1-016623-9. DOI: 10.1103/PhysRevE.72.016623

[9] CUMMER, S. A., POPA, B. I., SCHURIG, D., et al. Full wave simulations of electromagnetic cloaking structures. Physical Review E, 2006, vol. 74, no. 3, p. 036621-1-036621-5. DOI: 10.1103/PhysRevE.74.036621

[10] LANDY, N. I., SAJUYIGBE, S., MOCK, J. J., et al. Perfect metamaterial absorber. Physical Review Letters, 2008, vol. 100 no. 20, p. 207402-1-207402-4. DOI: 10.1103/PhysRevLett.100.207402

[11] BILOTTI, F., NUCCI, L., VEGNI, L. An SRR-based microwave absorber. Microwave and Optical Technology Letters, 2006, vol. 48, no. 11, p. 2171-2175. DOI: $10.1002 /$ mop. 21891

[12] DINCER, F., KARAASLAN, M., UNAL, E., et al. Design of polarization- and incident angle independent perfect metamaterial absorber with interference theory. Journal of Electronic Materials, 2014, vol. 43, no. 11 , p. 3949-3953. DOI: 10.1007/s11664-0143316-X

[13] SOHEILIFAR, M. R., SADEGHZADEH, R. A., GOBADI, H. Design and fabrication of a metamaterial absorber in the microwave range. Microwave and Optical Technology Letters, 2014, vol. 56, no. 8, p. 1748-1752. DOI: 10.1002/mop.28437

[14] ZHAI, H., LI, Z., LI, L., et al. A dual-band wide-angle -insensitive ultrathin gigahertz metamaterial absorber. Microwave and Optical Technology Letters, 2013, vol. 55, no. 7, p. 1606-1609. DOI: $10.1002 / \mathrm{mop} .27622$

[15] RAMYA, S., SRINIVASA RAO, I. Design of polarizationinsensitive dual band metamaterial absorber. Progress In Electromagnetics Research $M$, 2016, vol. 50, p. 23-31. DOI: 10.2528/PIERM16070501

[16] YOO, Y. J., KIM, Y. J., HWANG, J. S., et al. Triple-band perfect metamaterial absorption, based on single cut-wire bar. Applied Physics Letters, 2015, vol. 106, no.7, p. 071105-1-071105-5. DOI: $10.1063 / 1.4913243$
[17] BIAN, B., LIU, S., WANG, S., et al. Novel triple-band polarization insensitive wide-angle ultra-thin microwave metamaterial absorber. Journal of Applied Physics, 2013, vol. 114, no. 19 , p. 194511-1-194511-6. DOI: 10.1063/1.4832785

[18] BHATTACHARYA, A., BHATTACHARYYA, S., GHOSH, S., et al. An ultrathin pentaband polarization-insensitive compact metamaterial absorber for airborne radar applications. Microwave and Optical Technology Letters, 2015, vol. 57, no. 11, p. 2519 to 2524. DOI: $10.1002 / \mathrm{mop} .29365$

[19] LEE, J., LIM, S. Bandwidth-enhanced and polarization-insensitive metamaterial absorber using double resonance. Electronics Letters, 2011, vol. 47, no. 1, p. 8-9. DOI: 10.1049/el.2010.2770

[20] TAO, H., LANDY, N., BINGHAM, C. M., et al. A metamaterial absorber for the terahertz regime: design, fabrication and characterization. Optics Express, 2008, vol. 16, no. 10, p. 7181-7188. DOI: $10.1364 /$ OE.16.007181

[21] ZHANG, N., ZHOU, P., CHENG, D., et al. Dual-band absorption of mid-infrared metamaterial absorber based on distinct dielectric spacer layers. Optics Letters, 2013, vol. 38, no. 7, p. 1125-1127. DOI: 10.1364/OL.38.001125

[22] LI, S. J., CAO, X. Y., GAO, J., et al. Analysis and design of threelayer perfect metamaterial-inspired absorber based on double splitserration-rings structure. IEEE Transactions on Antennas and Propagation, 2015, vol. 63, no. 11, p. 5155-5160. DOI: 10.1109/TAP.2015.2475634

[23] BHATTACHARYYA, S., GHOSH, S., CHAURASIYA, D., et al. Bandwidth-enhanced dual-band dual-layer polarization-independent ultra-thin metamaterial absorber. Applied Physics A, 2015, vol. 118 , no. 1 , p. $207-215$. DOI: $10.1007 /$ s00339-014-8908-z

[24] LI, L., WANG, J., DU, H., et al. A band enhanced metamaterial absorber based on $\mathrm{E}$ shaped all-dielectric resonators. AIP Advances, 2015, vol. 5, p. 017147-1-017147-9. DOI: 10.1063/1.4907050

[25] LEE, J., LIM, S. Bandwidth-enhanced and polarization-insensitive metamaterial absorber using double resonance. Electronics Letters, 2011, vol. 47, no. 1, p. 8-9. DOI: 10.1049/el.2010.2770

[26] SOOD, D., TRIPATHI, C. C. A wideband wide-angle ultrathin low profile metamaterial microwave absorber. Microwave and Optical Technology Letters, 2016, vol. 58, no. 5, p. 1131-1135. DOI: $10.1002 / \mathrm{mop} .29741$

[27] BHATTACHARYYA, S., SRIVASTAVA, K. V. Triple band polarization-independent ultra-thin metamaterial absorber using electric field-driven LC resonator. Journal of Applied Physics, 2014, vol. 115, p. 064508-1-064508-7. DOI: 10.1063/1.4865273

[28] LIN, B. Q., ZHAO, S. H., DA, X. Y., et al. Design of an ultracompact metamaterial absorber. Microwave and Optical Technology Letters, 2015, vol. 57, no. 6, p. 1439-1441. DOI: 10.1002/mop.29099

[29] AYOP, O., RAHIM, M. K. A., MURAD, N. A., et al. Wideband polarization-insensitive metamaterial absorber with perfect dual resonances. Applied Physics A, 2016, vol. 122, no. 4, p. 1-7. DOI: 10.1007/s00339-016-9897-x

[30] AGARWAL, M., BEHERA, A. K., MESHRAM, M. K. Wideangle quad-band polarisation insensitive metamaterial absorber. Electronics Letters, 2016, vol. 52, no. 5, p. 340-342. DOI: $10.1049 / \mathrm{el} .2015 .4134$

[31] GHOSH, S., BHATTACHARYYA, S., KAIPRATH, Y., et al. Bandwidth-enhanced polarization-insensitive microwave metamaterial absorber and its equivalent circuit model. Journal of Applied Physics, 2014, vol. 115, no. 10, p. 104503-1-104503-5. DOI: $10.1063 / 1.4868577$

[32] ZHAI, H., ZHAN, C., LI, Z., et al. A triple band ultrathin metamaterial absorber with wide-angle and polarization stability. IEEE Antennas and Wireless Propagation Letters, 2015, vol. 14, p. 241-244. DOI: 10.1109/LAWP.2014.2361011 
[33] RAMYA, S., SRINIVASA RAO, I. A compact ultra-thin ultrawideband microwave metamaterial absorber. Microwave and Optical Technology Letters, 2017, vol. 59, p. 1837-1845. DOI: 10.1002/mop.30636

\section{About the Authors ...}

RAMYA SEKAR (corresponding author) was born in 1988. She received her M.Tech from VIT University
Vellore, India in 2014. Her research interests include metamaterial and microwave absorbers. She is currently working as an Assistant Professor and pursing Ph.D. in the School of Electronics Engineering, VIT, Vellore, India.

SRINIVASA RAO INABATHINI is currently working in VIT as an Associate Professor in the School of Electronics Engineering, Vellore, India. His research interests include microwave antenna, absorbers, and filters. 